\title{
Design and Implementation of the Control System of a Flat Surface Cleaning Robot
}

\author{
Zhen Jiujun ${ }^{*}$, , Gao Xin ${ }^{2}$, Yang Zhanmin ${ }^{3}$, Wang Xiaoyong ${ }^{1}$ and Song Haichao ${ }^{1}$ \\ ${ }^{I}$ College of Mechanical Engineering, Nanjing Institute of Industry Technology, Nanjing, Jiangsu, 210023, P.R. China \\ ${ }^{2}$ Department of Mechanical and Electrical Engineering, Hubei University of Science and Technology Tangshan Branch, \\ Tangshan, Hebei, 063000, P.R. China \\ ${ }^{3}$ College of Continuing Education, Nanjing Institute of Industry Technology, Nanjing, Jiangsu, 210023, P.R. China
}

\begin{abstract}
Through the analysis of needs of the flat surface cleaning, based on cleaning characteristics of smooth surface and the controlling method of the robot, a pneumatic flat surface cleaning robot based on PLC control is presented. The control system is mainly studied here. Firstly, the whole structure and running process of the robot is introduced. Secondly, the hardware part of the control system is introduced, including pneumatic system and electrical control system. Finally, software design and programming are expounded in detail. In particular, a unique analysis method used form in programming is presented. The using effect of the robot prototype shows that the control system of which core is PLC complies with the electrical standard and has a high cost performance. The robot can provide an effective way to replace artificial for the smooth flat surface cleaning, which is simple and safe.
\end{abstract}

Keywords: Control System, Software Design and Programming, Flat Surface Cleaning, Robot, PLC.

\section{INTRODUCTION}

With the development of the urban construction, the skyscrapers in large and medium sized cities are more and more. People has higher requirement for high-rise buildings, not only in function, but also more consideration to the building aesthetics. Glass curtain wall as an important symbol of the development of modern technology and construction level has become an important peripheral of high-rise building structure.

But after long-term use of high-rise buildings, the deposition on the surface of buildings seriously affects the beauty of tall buildings and the urban image. At present, the cleaning work of high-rise buildings is mainly done by manual, which the slightest mistake will be accidents, resulting in casualties to cleaning workers. Therefore, a device that can substitute for manual cleaning task of highrise buildings is much more paid attention to by engineering and technical personnel [1].

According to requirements of little noise in the city center, characteristics of wall cleaning that need a wide range and continuous operation, and considering the relative simple task of the cleaning device, common control method and the controller price, a pneumatic flat surface cleaning robot based on PLC control is presented.

*Address correspondence to this author at the College of mechanical engineering, Nanjing Institute of Industry Technology, Xianlin University City, Nanjing, Jiangsu, 210023, P.R. China; Tel: +86 13851556998;

E-mail: zhenjiujun@126.com

\section{DESIGN OF THE WHOLE STRUCTURE}

\subsection{The Mechanical Body}

The material of mechanical body adopts aluminum alloy which can greatly reduce the weight of the robot.

There are four small vacuum suckers 2 , two climbing cylinders 1 , one big vacuum sucker 3 , and one lifting cylinder 6 on Mechanical body. Suckers are used to finish vac-sorb function and cylinders are used to walk. There is one cleaning plates 5 installed on a cleaning cylinder for cleaning and there is also one camera 7 used for monitoring. According to the image transmitted by camera, the robot can move and clean in accordance with the instructions of operator. The multifunction rope 4 is used to protect the robot, when the robot drops accidentally. The mechanical body [2] of the robot is shown in Fig. (1) .

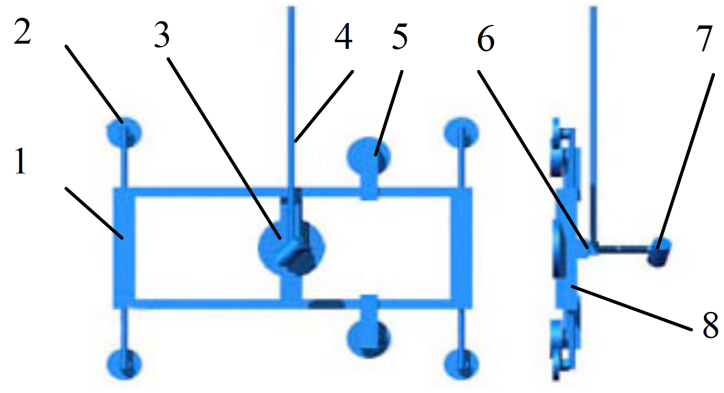

1. Climbing Cylinder. 2. Small Vacuum Sucker. 3. Big Vacuum Sucker. 4. Multifunction Rope. 5. Cleaning Cylinder and Cleaning Plate. 6. Lifting Cylinder. 7. Camera. 8. Rack.

Fig. (1). Mechanical body of robot. 
In order to achieve three kinds of status in the moving of the robot, a unique lifting cylinder 6 is adopted. The cylinder 6 is shown in Fig. (2).

The hardness of the spring 1 is greater than the spring 2 . When the two inlets $\mathrm{A}$ and $\mathrm{B}$ are connected with the atmosphere, spring 1 push the piston 1 to the down location, and spring2 push the piston 2 upward until touching piston1. So, the piston 2 is in the middle position.

When inlet $\mathrm{A}$ is connected with the high pressure gas and inlet $\mathrm{B}$ is connected with the atmosphere, piston 2 moves to the down location. So, the piston 2 is in the jacking position.

When inlet $\mathrm{B}$ is connected with the high pressure gas and inlet $\mathrm{A}$ is connected with the atmosphere, piston2 and piston 1 moves to the up location. So, the piston 2 is in the contraction position.

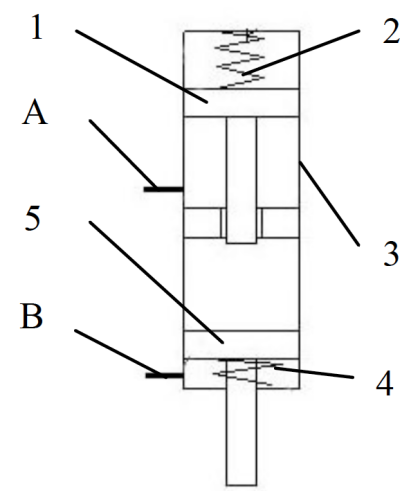

A. Gas Path. B. Gas Path. 1. Cylinder1. 2. Spring1. 3. Cylinder Block. 4. Spring2. 5. Cylinder2.

Fig. (2). Lifting cylinder.

So the lifting cylinder 6 is easy to produce three kinds of status to finish the moving of robot.

\subsection{The Working Process}

To understand the working process of the cleaning robot, the key is to understand the action of adsorption, climbing and cleaning.

According to the three kinds of status of lifting cylinder 6 , walking process of the robot can be divided into the following three steps. The system can achieve the status through controlling the vacuum suckers and climbing cylinders 1 to adhere on the flat surface and move.

The first step is the status of contraction position of the lifting cylinder 6 . During this period, the vacuum sucker 3 is in a state of leaving the flat surface, and the four vacuum suckers2 are in a state of contacting flat surface. The pressure inside the vacuum sucker3 is standard atmospheric pressure; the pressure inside the four vacuum suckers2 is negative pressure which makes the robot adsorb on the flat surface. The robot can move ahead, when pistons of climbing cylinders 1 on both sides of the robot retract.

The second step is the status of middle position of the lifting cylinder6. All the vacuum suckers are in a state of contacting flat surface. At the beginning, the pressure inside all vacuum suckers is negative pressure. And then, the pressure inside the four vacuum suckers 2 is standard atmospheric pressure; the pressure inside the vacuum suckers3 is negative pressure which makes the robot adsorb on the flat surface.

The third step is the status of jacking position of the lifting cylinder6. The vacuum sucker 3 is in a state of contacting flat surface, and the four vacuum suckers 2 are in a state of leaving the flat surface. Then the pistons of climbing cylinders 1 on both sides of the robot extend, which prepare for the next moving forward of the robot.

In order to make the robot work reliably, cleaning work should be began during the pierod of four vacuum suckers2 adhering on the flat surface. Through the operation button shown in Fig. (10), the operator can control the reciprocating movement of cleaning cylinder and plate 5 to clean.

\section{DESIGN OF HARDWARE SYSTEM}

The system includes the pneumatic part and the electrical part which are mainly composed of PLC controller, vacuum switch, magnetic switches, solenoid valve, etc. The block diagram of the hardware system [3] is shown in Fig. (3).
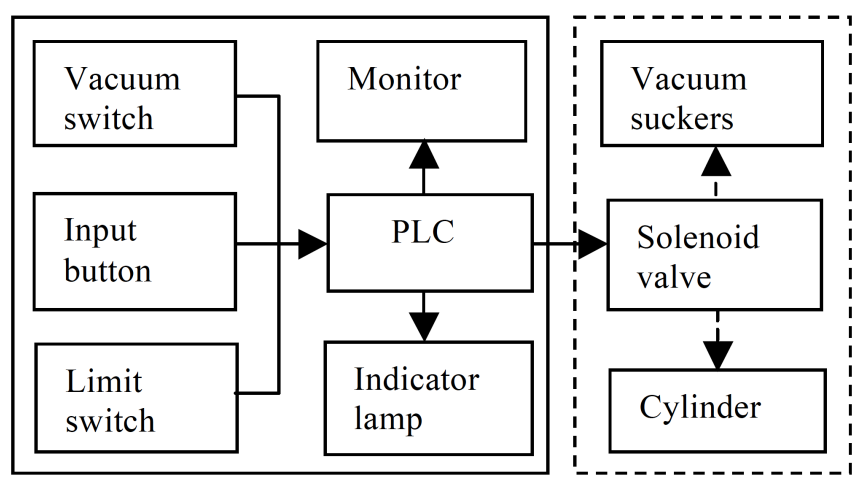

Fig. (3). Block diagram.

The diagram in solid line box is the circuit parts, and the diagram in the dotted line box is the pneumatic parts.

\subsection{The Pneumatic Circuit}

Power of the system comes from the pneumatic system. The pneumatic system is made up of the auxiliary pneumatic circuit, the cylinder driven pneumatic circuit and the vacuum pneumatic circuit. The schematic is shown in Fig. (4) [4].

The auxiliary pneumatic circuit consists of FR and V0. FR is filter and regulator combination which is used to purify the air and regulate air pressure. V0 is two two-way manual valve which is used to control the on-off of the entire pneumatic circuit.

The cylinder driven pneumatic circuit consists of $\mathrm{C} 1 \sim \mathrm{C} 3$, L1 L6, SP1 SP4 and V3 V6. C1 C3 are climbing cylinder1, lifting cylinder6 and cleaning cylinder5 (shown in Fig. 1). L1 L6 are one-way throttle valves used to control the speed of the cylinder piston rod. SP1 SP4 are magnetic switches of which function are to detect the position of the cylinder piston. V3 and V6 are two five-way solenoid valves; V4 and V5 are two three-way solenoid valves which are used to control the extending and retracting action of cylinder piston rods. 


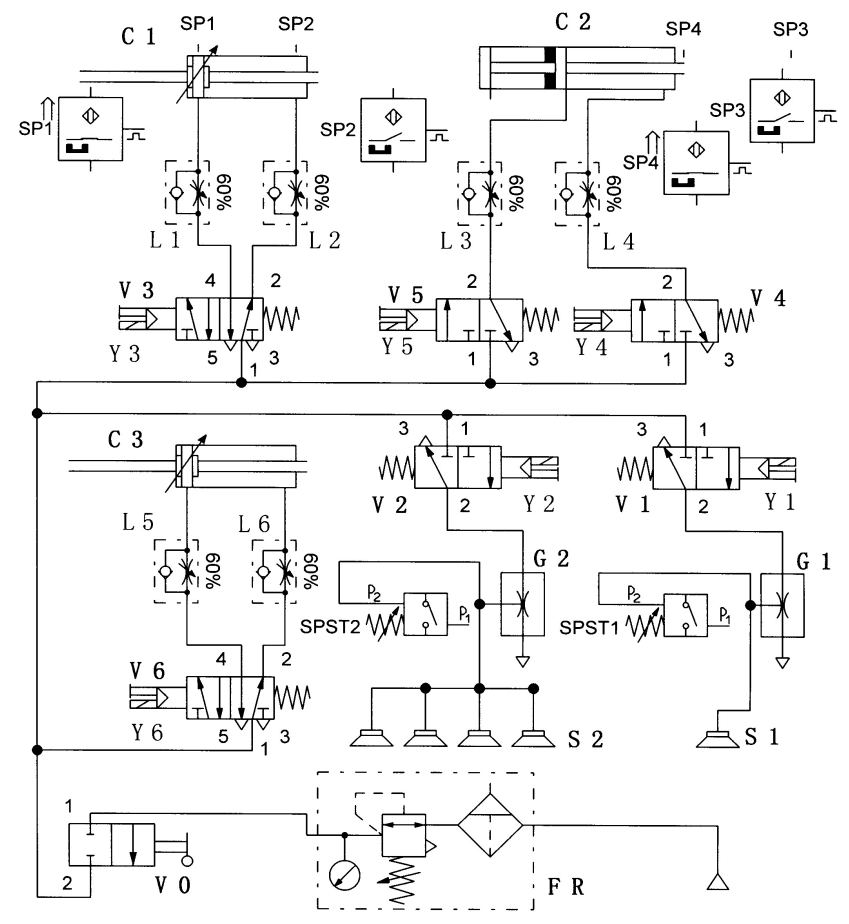

Fig. (4). Pneumatic schematic.

The vacuum pneumatic circuit consists of S1, S2, SPST1, SPST2, G1, G2, V1 and V2. S1 and S2 are the big vacuum sucker3 and four small vacuum suckers2 (shown in Fig. 1). SPST1 and SPST2 are differential pressure switches. G1 and G2 are vacuum generators. V1 and V2 are two three-way solenoid valves.

\subsection{Design of the Electrical Part}

The commonly used controller are Single Chip Microcomputer, PLC, ARM, etc.. Considering simplification and the cost of technology, the reliability of the system, the Siemens S7-200CN programmable logic controller is adopted in the control system.

According to the control command of the operator and the feedback signal of vacuum switch or magnetic switches, through controlling solenoid valve to energize or deenergize, to connect or disconnect the air line of cylinder, The PLC can drive the robot to climb or fall. The hard lines are used to communicate between PLC and the robot, which has strong anti-jamming capability. Fig. (5) is the electrical schematics of PLC control system [5].

SPST1 and SPST2 are the signals of vacuum. SP1, SP2, SP3 and SP4 are the signals of magnetic switches. Y1, Y2, Y3, Y4, Y5 and Y6 are solenoid valves of the selector valves. They respectively correspond to devices in Fig. (4). SB1, SB2 SB3, SB4, SB5 and SB6 are the corresponding input signal of the manual buttons. Q0.6, Q0.7, Q1.0 and Q1.1 are the corresponding status indicators.

\section{DESIGN OF SOFTWARE SYSTEM}

Through the remote control, the Cleaning robot can finish the corresponding work [6]. When the lifting cylinder6 in the jacking position or contraction position, press the climbing button SB1, climbing cylinder will work in climbing way; press the falling button SB2, climbing cylinder will work in falling way. Cleaning and stop button control the start or stop of cleaning cylinder and cleaning plate 5 .

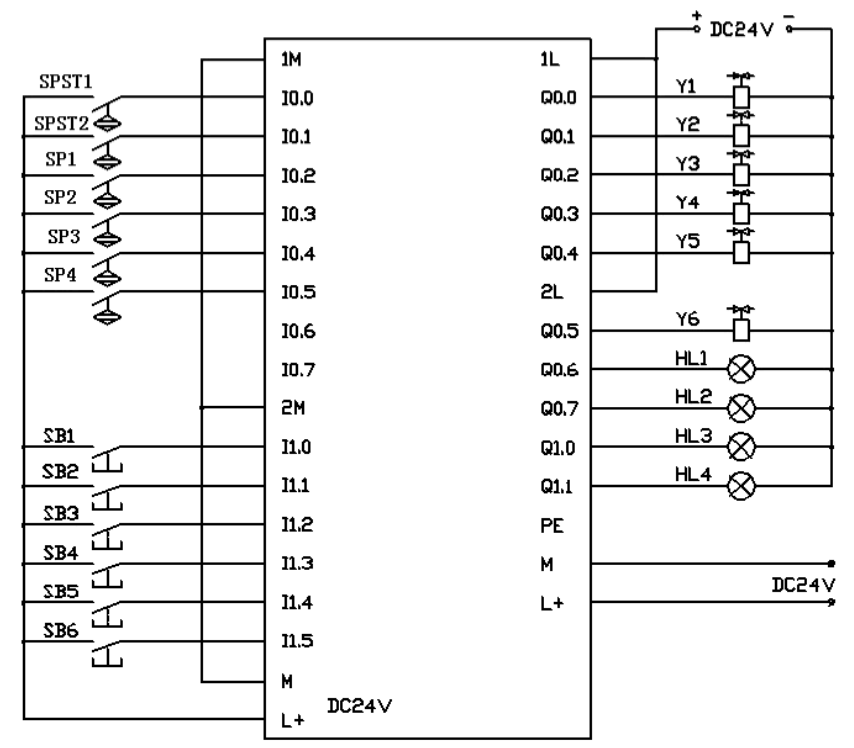

Fig. (5). Electrical schematics.

\subsection{Motion Analysis}

Solenoid valve Y1, Y2 and Y3 are used to control the climbing and vacuum status of suckers3 and sucker2 shown in Fig. (4).

When solenoid valve $\mathrm{Y} 1$ is energized, the suckers 3 are in vacuum status, otherwise suckers 3 is in atmospheric pressure status. When solenoid valve Y2 is energized, the sucker2 is in vacuum status, otherwise sucker2 is in atmospheric pressure status. When solenoid valve $\mathrm{Y} 3$ is energized, the suckers3 are used to climb, otherwise the sucker2 is used to climb.

Solenoid valve Y4 and Y5 are used to control the jacking or contraction actions of the lifting cylinder.

When solenoid valve Y4 and solenoid valve Y5 are deenergized at the same time, the lifting cylinder6 is in a jacking status. When solenoid valve Y4 and solenoid valve Y5 are energized, the lifting cylinder6 is in a contraction status. When solenoid valve Y4 is de-energize and Solenoid valve Y5 is energize, the lifting cylinder6 is in a middle status.

Solenoid valve Y6 is used to control the cleaning actions of the robot. The reciprocating movement of the cleaning cylinder is controlled by solenoid valve $\mathrm{Y} 6$ which is energized or de-energized according to a certain time interval of the timer of PLC.

\subsubsection{The Initial Status}

In this status, the piston rod of lifting cylinder6 retract, and the four small vacuum suckers which contact with the flat surface are in a negative pressure status. Through adsorption force of the four small vacuum suckers, the robot 
is fixed to the flat surface. At this time, solenoid valve $\mathrm{Y} 3$ is energized and climbing cylinders are in extended position.

\subsubsection{Climbing Movement.}

Climbing movement can be divided into two steps.

Step one: the four small vacuum suckers3 are in vacuum status; solenoid valve Y3 is de-energized; compressed air goes into the upper of climbing cylinders, the body of robot goes up.

Step two: The lifting cylinder6 is in a jacking status; big vacuum sucker2 is in vacuum status; solenoid valve Y3 is energized; compressed air goes into the bottom of climbing cylinders, piston rods of climbing cylinders go up. Climbing state table is shown in Table $\mathbf{1 .}$

Table 1. Process of climbing and device status.

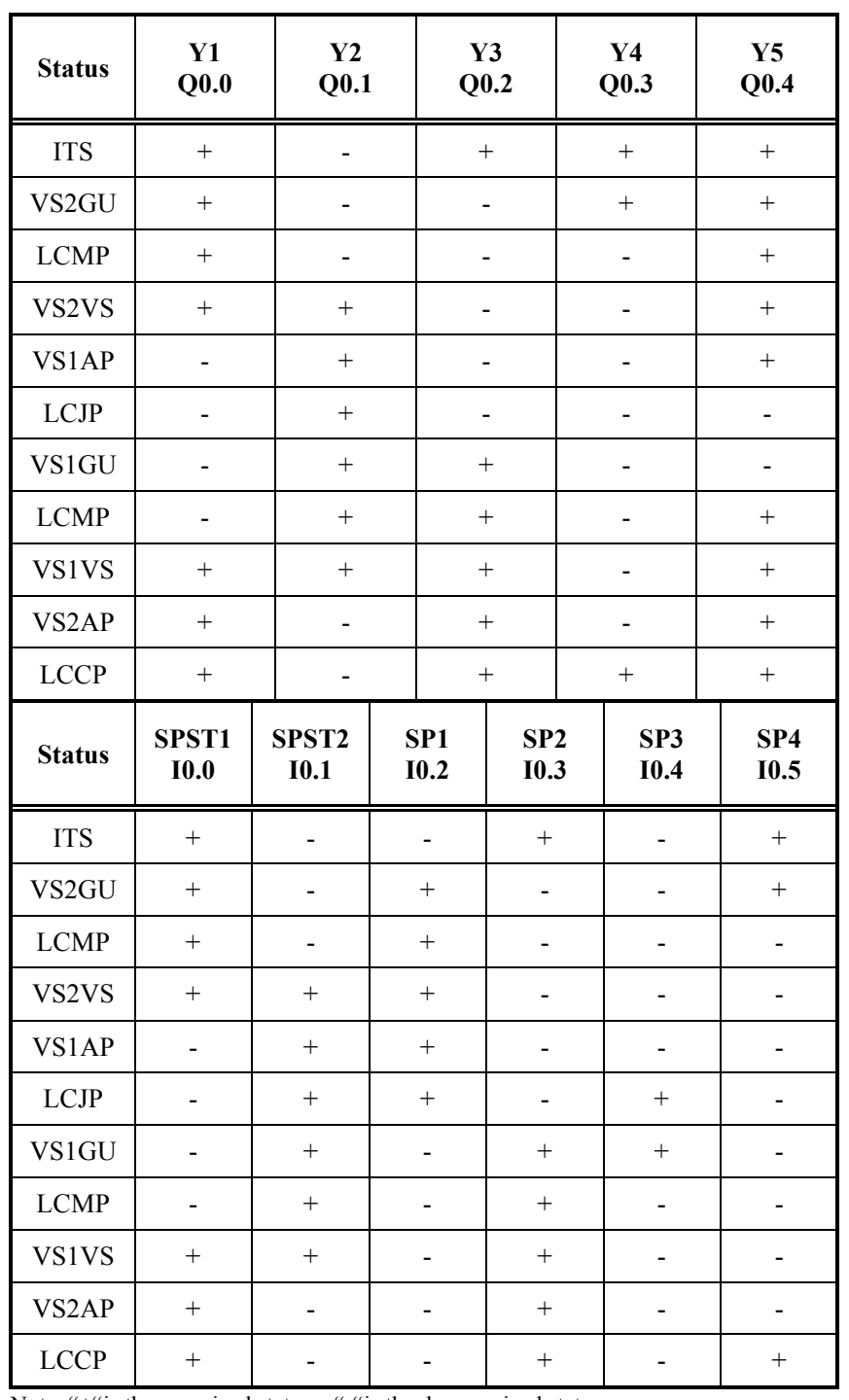

Note: "+"is the energized status ; "-"is the de-energized status.

The means of abbreviations in Table 2 are explained as follows:

(1) ITS--The Initial State.

(2) VS2GU-- Vacuum Sucker 2 goes up.
(3) VS1GU-- Vacuum Sucker3 goes up.

(4) VS2GD-- Vacuum Sucker 2 goes down.

(5) VS1GD-- Vacuum Sucker3 goes down.

(6) LCMP-- Middle position of lifting cylinder6.

(7) LCCP-- Contraction position of lifting cylinder6.

(8) LCJP-- Jacking position of lifting cylinder6.

(9) VS2VS--Negative pressure status of vacuum sucker2.

(10) VS1VS--Negative pressure status of vacuum sucker3.

(11) VS1AP--Vacuum Sucker3 is in a atmospheric pressure state.

(12) VS1AP--Standard atmospheric pressure status of vacuum sucker3.

(13) VS2AP-- Standard atmospheric pressure status of vacuum sucker2.

\subsubsection{Falling Movement}

Fallinging movement can also be divided into two steps.

Step one: The lifting cylinder6 is in jacking status; big vacuum sucker2 is in negative pressure status; solenoid valve Y3 is de-energized. Compressed air goes into the upper of climbing cylinders, and then the piston rods of the climbing cylinders(Vacuum Sucker 1) go down.

Step two: The lifting cylinder6 is in a contraction status; the four small vacuum suckers3 are in negative pressure status; solenoid valve Y3 is energized; compressed air goes into the bottom of climbing cylinders; the body of the robot goes down. Climbing state table is shown in Table 2.

The abbreviations in Table 2 have been shown in the note of Table $\mathbf{1}$.

\subsubsection{Jacking and Contracting Action Status of Lifting Cylinder}

These two actions are mainly used to debug the robot. Jacking action status is shown in Table 3; Contracting action status is shown in Table 4.

The abbreviations in Table $\mathbf{3}$ have been shown in the note of Table $\mathbf{1}$.

The abbreviations in Table $\mathbf{4}$ have been shown in the note of Table 1 .

To ensure that there must be at last one of thesuckers3 and sucker2 in the adsorption status, solenoid valve $\mathrm{Y} 1$ or Y2 must be energized or de-energized controlled by PLC program according to the status of the Vacuum Switch, which make the status ofsuckers3and sucker2 alternate between adsorption and release.

\subsection{Design of Program}

To write programs, we must firstly allocate the name of $\mathrm{I} / \mathrm{O}$ and address.

\subsubsection{Allocation of I/O Address}

$\mathrm{I} / \mathrm{O}$ name and address allocation table of PLC is shown in Table 5. 
Table 2. Process of falling and device status.

\begin{tabular}{|c|c|c|c|c|c|c|c|}
\hline Status & $\begin{array}{c}\text { Y1 } \\
\text { Q0.0 }\end{array}$ & $\begin{array}{c}\text { Y2 } \\
\text { Q0.1 }\end{array}$ & \multicolumn{3}{|c|}{$\begin{array}{c}\text { Y3 } \\
\text { Q0.2 }\end{array}$} & $\begin{array}{c}\text { Y4 } \\
\text { Q0.3 }\end{array}$ & $\begin{array}{c}\text { Y5 } \\
\text { Q0.4 }\end{array}$ \\
\hline ITS & + & - & & + & & + & + \\
\hline LCMP & + & - & & + & & - & + \\
\hline VS2VS & + & + & & + & & - & + \\
\hline VS1AP & - & + & & + & & - & + \\
\hline LCJP & - & + & & + & & - & - \\
\hline VS1GD & - & + & & - & & - & - \\
\hline LCMP & - & + & & - & & - & + \\
\hline VS1VS & + & + & & - & & - & + \\
\hline VS2AP & + & - & & - & & - & + \\
\hline LCCP & + & - & & - & & + & + \\
\hline VS2GD & + & - & & + & & + & + \\
\hline Status & $\begin{array}{c}\text { SPST1 } \\
\text { I0.0 }\end{array}$ & $\begin{array}{c}\text { SPST2 } \\
\text { I0.1 }\end{array}$ & $\begin{array}{l}\text { SP1 } \\
\text { I0.2 }\end{array}$ & & $\begin{array}{l}\text { SP2 } \\
\text { I0.3 }\end{array}$ & $\begin{array}{l}\text { SP3 } \\
\text { I0.4 }\end{array}$ & $\begin{array}{l}\text { SP4 } \\
\text { I0.5 }\end{array}$ \\
\hline ITS & + & - & - & & + & - & + \\
\hline LCMP & + & - & - & & + & - & - \\
\hline VS2VS & + & + & - & & + & - & - \\
\hline VS1AP & - & + & - & & + & - & - \\
\hline LCJP & - & + & - & & + & + & - \\
\hline VS1GD & - & + & + & & - & + & - \\
\hline LCMP & - & + & + & & - & - & - \\
\hline VS1VS & + & + & + & & - & - & - \\
\hline VS2AP & + & - & + & & - & - & - \\
\hline LCCP & + & - & + & & - & - & + \\
\hline VS2GD & + & - & - & & + & - & + \\
\hline
\end{tabular}

Note: "+"is the energized status ; "-"is the de-energized status.

Table 3. Jacking action status of lifting cylinder.

\begin{tabular}{|c|c|c|c|c|c|c|}
\hline Status & $\begin{array}{c}\text { Y1 } \\
\text { Q0.0 }\end{array}$ & $\begin{array}{c}\text { Y2 } \\
\text { Q0.1 }\end{array}$ & \multicolumn{2}{|r|}{$\begin{array}{c}\text { Y3 } \\
\text { Q0.2 }\end{array}$} & $\begin{array}{c}\text { Y4 } \\
\text { Q0.3 }\end{array}$ & $\begin{array}{c}\text { Y5 } \\
\text { Q0.4 }\end{array}$ \\
\hline ITS & + & - & \multicolumn{2}{|r|}{+} & + & + \\
\hline LCMP & + & - & \multicolumn{2}{|r|}{+} & - & + \\
\hline VS2VS & + & + & \multicolumn{2}{|r|}{+} & - & + \\
\hline VS1AP & - & + & \multicolumn{2}{|r|}{+} & - & + \\
\hline LCJP & - & + & \multicolumn{2}{|r|}{+} & - & - \\
\hline Status & $\begin{array}{c}\text { SPST1 } \\
\text { I0.0 }\end{array}$ & $\begin{array}{c}\text { SPST2 } \\
\text { I0.1 }\end{array}$ & $\begin{array}{l}\text { SP1 } \\
\text { I0.2 }\end{array}$ & & $\begin{array}{l}\text { SP3 } \\
\text { I0.4 }\end{array}$ & $\begin{array}{l}\text { SP4 } \\
\text { I0.5 }\end{array}$ \\
\hline ITS & + & - & - & & - & + \\
\hline LCMP & + & - & - & & - & - \\
\hline VS2VS & + & + & - & & - & - \\
\hline VS1AP & - & + & - & & - & - \\
\hline LCJP & - & + & - & & + & - \\
\hline
\end{tabular}

Note: "+"is the energized status ; "“"is the de-energized status.
Table 4. Contracting action status of lifting cylinder.

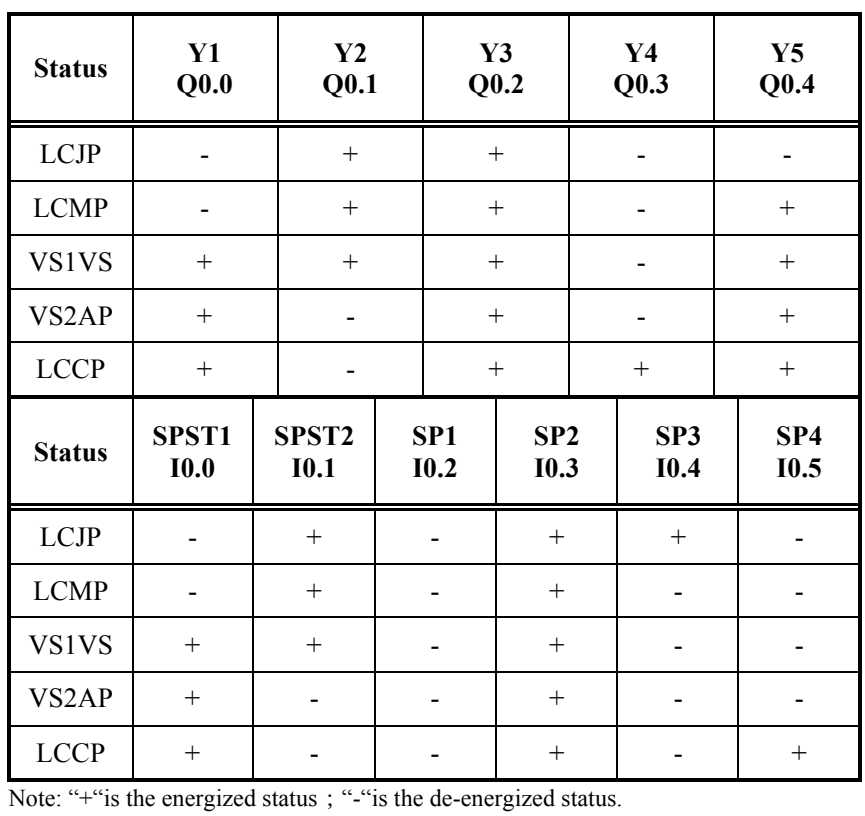

Table 5. I/O name and address allocation table.

\begin{tabular}{|c|c|c|}
\hline Name & Address & Annotation \\
\hline SPST1 & $\mathrm{I} 0.0$ & Vacuum Switch 1 \\
\hline SPST2 & I0.1 & Vacuum Switch 2 \\
\hline SP1 & $\mathrm{I} 0.2$ & Magnetic switches1 \\
\hline SP2 & $\mathrm{I} 0.3$ & Magnetic switches2 \\
\hline SP3 & $\mathrm{I} 0.4$ & Magnetic switches3 \\
\hline SP4 & $\mathrm{I} 0.5$ & Magnetic switches 4 \\
\hline SB1 & I1.0 & Button of Climbing \\
\hline SB2 & I1.1 & Button of Falling \\
\hline SB3 & $\mathrm{I} 1.2$ & $\begin{array}{c}\text { Button of Jacking } \\
\text { Action of Lifting Cylinder }\end{array}$ \\
\hline SB4 & I1.3 & $\begin{array}{l}\text { Button of Contracting } \\
\text { Action of Lifting Cylinder }\end{array}$ \\
\hline SB5 & $\mathrm{I} 1.4$ & Button of Cleaning \\
\hline SB6 & I1.5 & Button of Stop \\
\hline Y1 & Q0.0 & $\begin{array}{l}\text { Solenoid valve 1; "1": } \\
\text { Vacuum Sucker } 1 \text { is in vacuum status }\end{array}$ \\
\hline Y2 & Q0.1 & $\begin{array}{l}\text { Solenoid valve } 2 \text {; "1": } \\
\text { Vacuum Sucker2 is in vacuum status; }\end{array}$ \\
\hline Y3 & Q 0.2 & $\begin{array}{l}\text { Solenoid valve 3; "1": } \\
\text { Vacuum Sucker 1goning up }\end{array}$ \\
\hline Y4 & Q0.3 & Solenoid valve 4 \\
\hline Y5 & Q0.4 & Solenoid valve 5 \\
\hline Y6 & Q0.5 & Solenoid valve 6; "1": cleaning \\
\hline HL1 & Q0.6 & Indicator Lamp of Climbing \\
\hline HL2 & Q0.7 & Indicator Lamp of Falling \\
\hline HL3 & Q1.0 & Indicator Lamp of Cleaning \\
\hline HL4 & Q1.1 & Indicator Lamp of initial status \\
\hline
\end{tabular}


After the address is determined, programs can be written. The programming is divided into the main program and subroutines.

\subsubsection{Design of Main Program}

The main program is shown in Fig. (6).

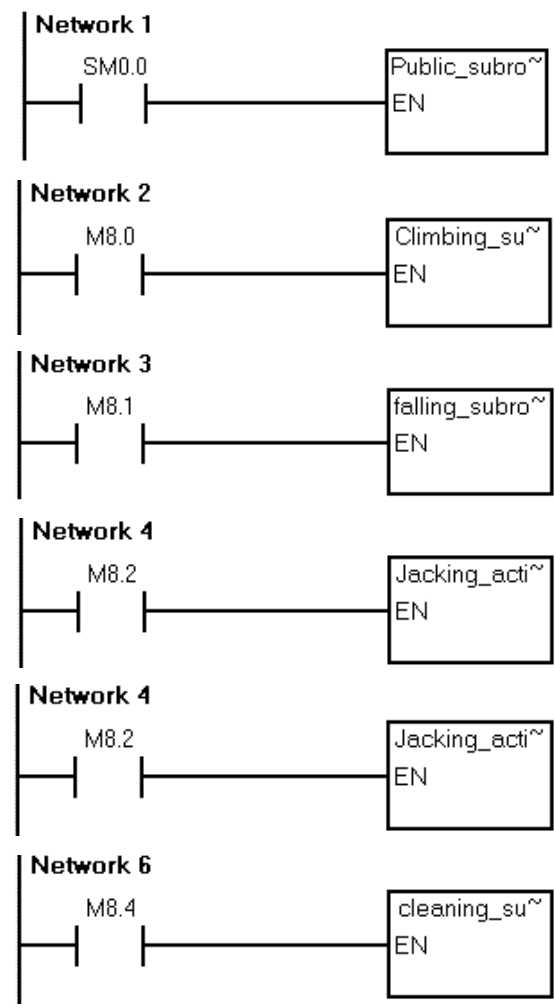

Fig. (6). The main program.

When PLC is in running status, SM0.0 equals to logic 1 and the normally open contact of SM0.0 is always closed. So, public subroutine is executed unconditionally.

When button of climbing is pressed, M8.0 is on and the climbing subroutine is performed. When button of falling is pressed, M8.1 is on and the falling subroutine is performed. When button of jacking is pressed, M8.2 is on and the jacking action subroutine is performed. When button of contracting is pressed, M8.3 is on and the contracting action subroutine is performed. When button of cleaning is pressed, M8.4 is on and the cleaning subroutine is performed.

\subsubsection{Public Subroutine}

Public subroutine is used to the initialize the program and to call different subroutines according to corresponding conversion conditions. The public subroutine is shown in Fig. (7).

Network1 is used to initialize the registers; Network2 is used to detect the initial status of the robot. M3.0 is the symbol of the initial status of the robot. When the robot is in line with initial status, M3.0 = 1; Network3 is used to go into the climbing subroutine; Network4 is used to go into falling subroutine; Network5 is used to go into jacking action subroutine; Network6 is used to go into contracting action subroutine; Network 7 is used to go into cleaning subroutine.

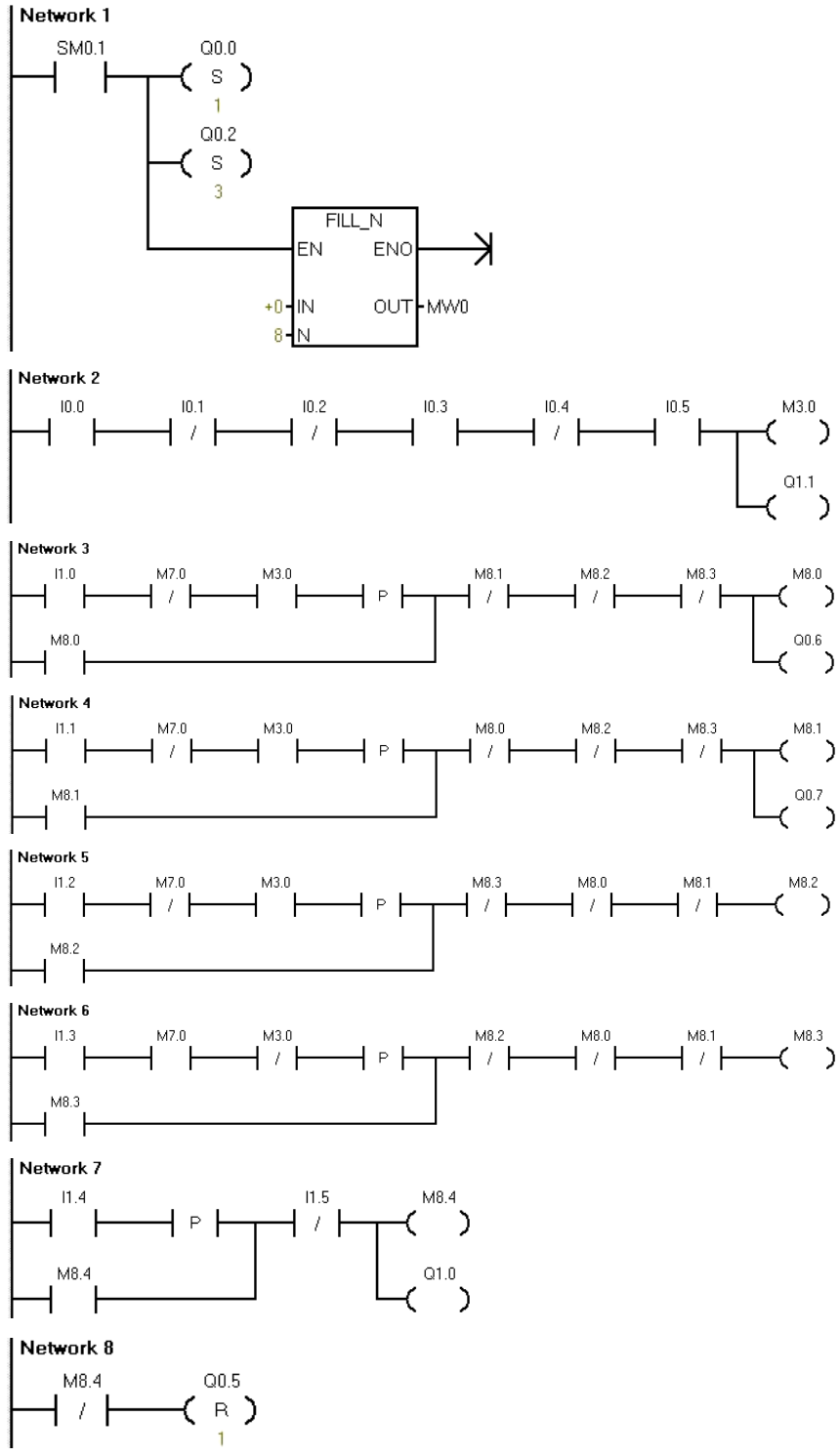

Fig. (7). Public subroutine.

\subsubsection{Climbing Subroutine}

When you press the climbing button, the robot can move forward on the flat surface.

According to Table 2 (Process of Climbing and Device Status), climbing process includes eleven kinds of status. They are in turn the initial status, vacuum sucker2 going up, the lifting cylinder6 being in the middle status, vacuum sucker2 being in vacuum status, vacuum suckers 3 beng in a atmospheric pressure status, the lifting cylinder6 being in the jacking status, vacuum suckers 3 going up, the lifting cylinder6 being in the middle status, vacuum suckers 3 being in vacuum status, vacuum sucker2 beng in a atmospheric pressure status, and the lifting cylinder bein in a contraction position. The above eleven corresponding status are indicated by the memory $\mathrm{M}$.

Based on the above analysis, a sequential function chart can be drawn, which is shown in Fig. (8).

Other subroutines such as falling subroutine, jacking action subroutine, contracting action subroutine, and 


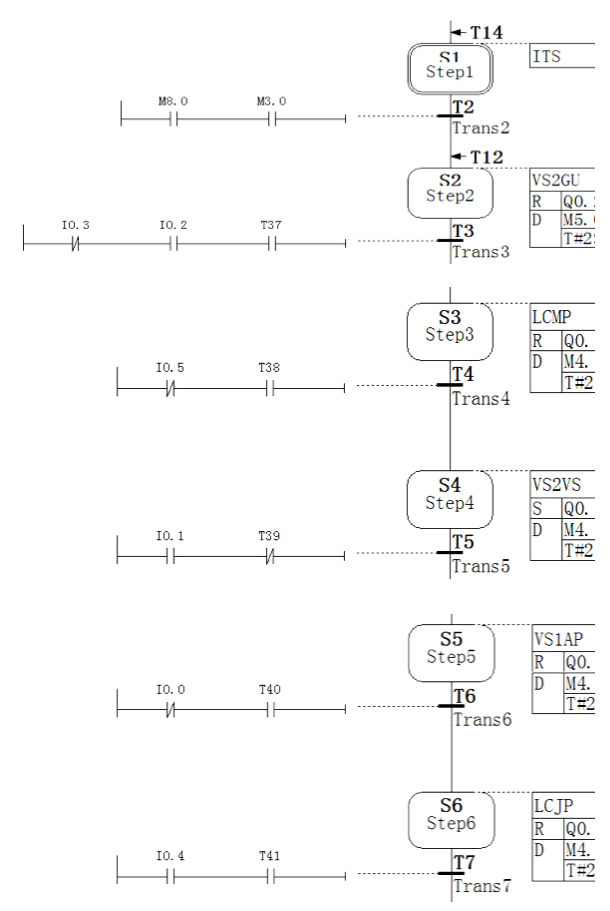

Fig. (8). Sequential function chart of climbing subroutine.

cleaning subroutine will no longer be introduced here. They can be written with the same method as above subroutines.

\section{CONCLUSION}

A kind of compressed air pressure-driven and PLC controlled crawling and cleaning robot is explained in detail in this paper. The robots can be reliably adsorbed and move on a flat surface while accomplishing the cleaning tasks. The robot prototype is shown in Fig. (9).

The control system of robot using PLC as the control core has characteristics of the high reliability, low cost and is simple in structure, easy to operate. The hardware of control system is shown in Fig. (10).

There are six buttons in the control box. They are climbing button, falling button, jacking button, contracting button, cleaning button, and stop button. The operator of the robot can finish the cleaning tasks through corresponding action buttons.

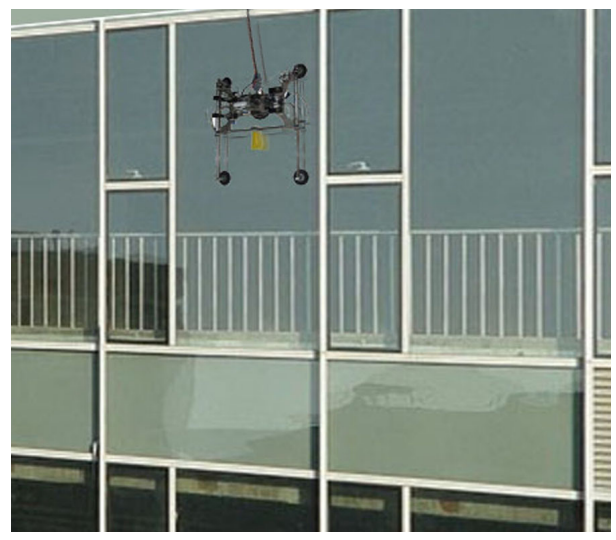

Fig. (9). the prototype of the robot.
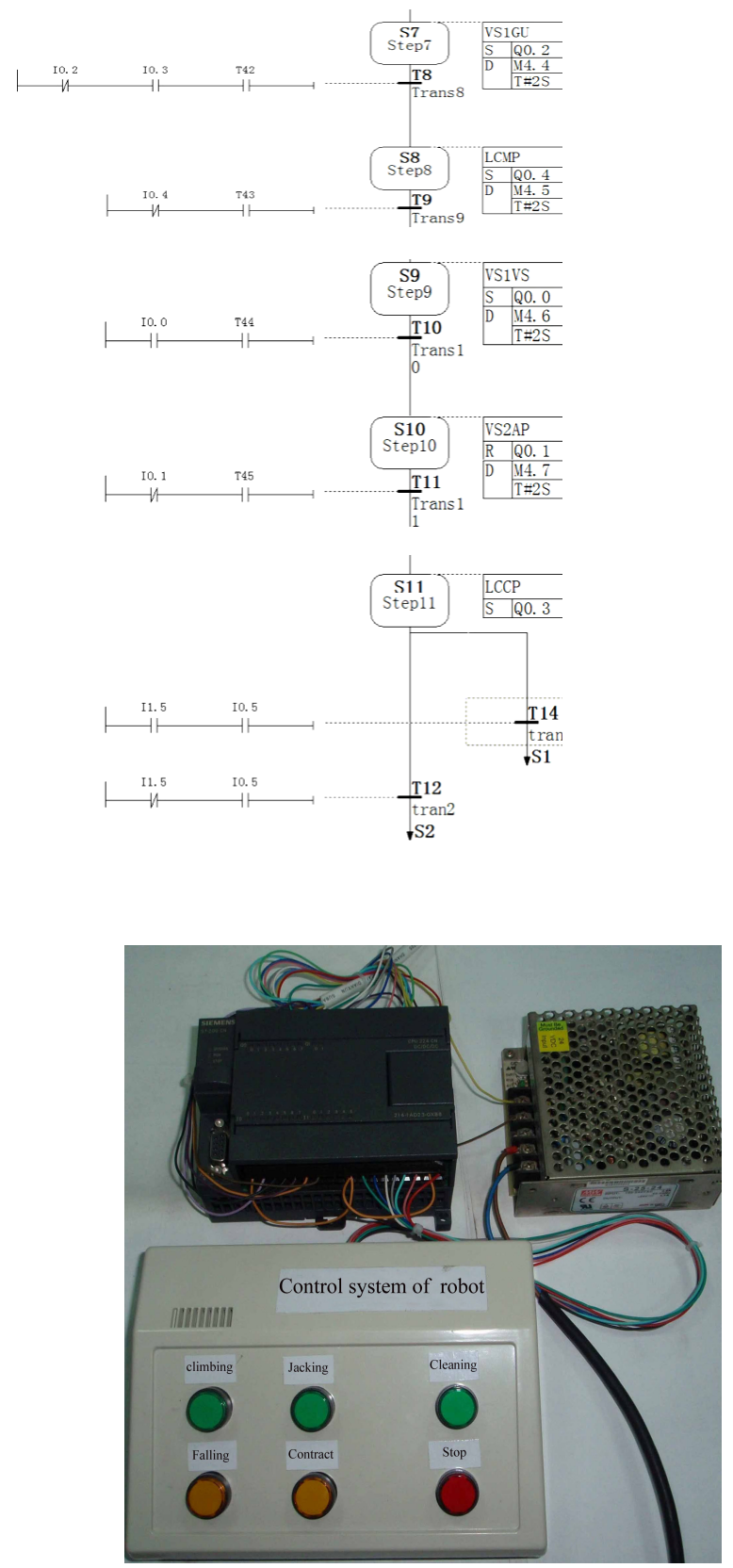

Fig. (10). The control system.

The using effect of the robot prototype shows that the control system of which core is PLC complies with the electrical standard and has a high cost performance. The robot can provide an effective way to replace artificial for the smooth flat surface cleaning, which is simple and safe..

\section{CONFLICT OF INTEREST}

The authors confirm that this article content has no conflict of interest.

\section{ACKNOWLEDGEMENTS}

This work is supported by Open Foundation of Precision Manufacturing Engineering and Technology Research and Development Centers of Jiangsu Province (NO. ZK12-01- 
02) and also sponsored by Qing Lan Project of Jiangsu Province.

\section{REFERENCES}

[1] H. Zhang, J. Zhang, and G. Zong, "Requirements of glass cleaning and development of climbing robot systems", In: Proceedings of the 2004 International Conference on Intelligent Mechatronics and Automation, Chengdu, China, pp. 101-106, 2004.

[2] J. Zhen, and Z. Zhao, "Study of pneumatic glass-wall cleaning robots", In: International Conference on Computer Science and Information Processing (CSIP), Shaanxi, China, pp. 664-667, 2012.
[3] A. Nishi, and H. Miyagi, "Mechanism and control of propeller type wall-climbing robot", In: Proceedings of the 1994 IEEE/RSJ/GI International Conference on Intelligent Robots and System, Newyork, USA, pp. 1724-1729, 1994.

[4] H. Zhang, and G. Zong, "Pneumatic robot for glass-wall cleaning", Chinese Hydraulics\& Pneumatics, vol. 11, pp. 5-8, 2001.

[5] L. Chengqun, T. Chao, W. Baoliu, and P. Wei, "Application of PLC in the robot flexible polishing machine", Manufacturing Automation, vol. 29, no.7, pp. 27-30, 2007.

[6] T. Akinfiev, M. Armada, and S. Nabulsi, "Climbing cleaning robot for vertical surfaces", Industrial Robot: An International Journal, vol. 36, no. 4, pp. 352-357, 2009.

(C) Jiujun et al.; Licensee Bentham Open.

This is an open access article licensed under the terms of the (https://creativecommons.org/licenses/by/4.0/legalcode), which permits unrestricted, non-commercial use, distribution and reproduction in any medium, provided the work is properly cited. 